\title{
Squeal Frequency of a Railway Disc Brake Evaluation by FE Analyses
}

\author{
F. Cascetta, F. Caputo $\mathbb{D}$, and A. De Luca $(\mathbb{D}$ \\ Department of Industrial and Information Engineering, Second University of Naples, Via Roma 29, 81031 Aversa, Italy \\ Correspondence should be addressed to F. Caputo; francesco.caputo@unicampania.it
}

Received 20 November 2017; Revised 5 February 2018; Accepted 1 March 2018; Published 15 April 2018

Academic Editor: Kim M. Liew

Copyright (c) 2018 F. Cascetta et al. This is an open access article distributed under the Creative Commons Attribution License, which permits unrestricted use, distribution, and reproduction in any medium, provided the original work is properly cited.

\begin{abstract}
This paper deals with the development of a numerical model, based on the Finite Element (FE) theory for the prediction of the squeal frequency of a railway disc brake. The analytical background has been discussed and presented, as well as the most efficient methods for evaluating the system stability; the attention has been paid particularly to the complex eigenvalues method, which has been adopted within this paper to investigate the railway disc brake system. Numerical results have been compared with measurements from experimental tests in order to validate the proposed numerical approach. At the end of this work, a sensitivity analysis, aimed at understanding the effects of some physical parameters influencing the stability of the brake system and the squeal propensity, has been carried out.
\end{abstract}

\section{Introduction}

The high ecological value of rail transport is recognized by the public opinion and widely demonstrated by scientific literature. This has led to an increase of rail transport for handling both goods and passengers [1]. However the Green Paper Future Noise Policy of November 1996 [2], proposed by the European Commission, states that the "public's main criticism of rail transport is the excessive noise level." Therefore, the WG Railway Noise of the European Commission prepared on 2003 a Position Paper in order to provide guidance on possible European strategies and priorities for railway noise abatement [3], thoroughly investigated in several research projects [4-15] funded by the European Community and by European Rail Research Institute (ERRI).

With reference to the Train à Grande Vitesse (TGV), a main noise source annoying passengers inside the train, as well as people at the station, is the brakes squeal $[16,17]$. The brake squeal is an unstable vibration caused by a geometric instability and by a negative coefficient of friction-velocity slope. It can be split into two categories: low frequency and high frequency squeals [18]. Low frequency squeal is generally classified as noise having a narrow frequency bandwidth, above $1000 \mathrm{~Hz}$, but below the first circumferential (longitudinal) rotor mode. The failure mode for this category of squeal can be associated with frictional excitation coupled with a phenomenon referred to as "modal locking" of brake corner components. Modal locking is the coupling of two or more modes of various structures producing favorable conditions for brake squeal triggering. High frequency brake squeal is, instead, defined as noise produced by friction induced excitation, imparted by coupled resonances (closely spaced modes) of the rotor itself as well as of other brake corner components. Typically, it is classified as squeal occurring at frequencies above $5 \mathrm{kHz}$.

In general, structural and acoustic modeling methods, used to predict the performance in terms of noise and vibration, have become the key tools in the design process [19-22].

In this paper the stability of a disc brake system for a TGV and its squeal propensity has been investigated by means of a numerical model based on Finite Element Method (FEM). In particular, the test article has been manufactured by Ecobrake S.u.r.l. for a high speed train of Italian Railway. The numerical model has been assessed by comparing the predicted frequencies at which disc brake squeal occurs, with those obtained in Sinou et al. [17]. Sinou et al. investigated a different disc brake system, whose structural component is similar to the investigated test article. The differences, 


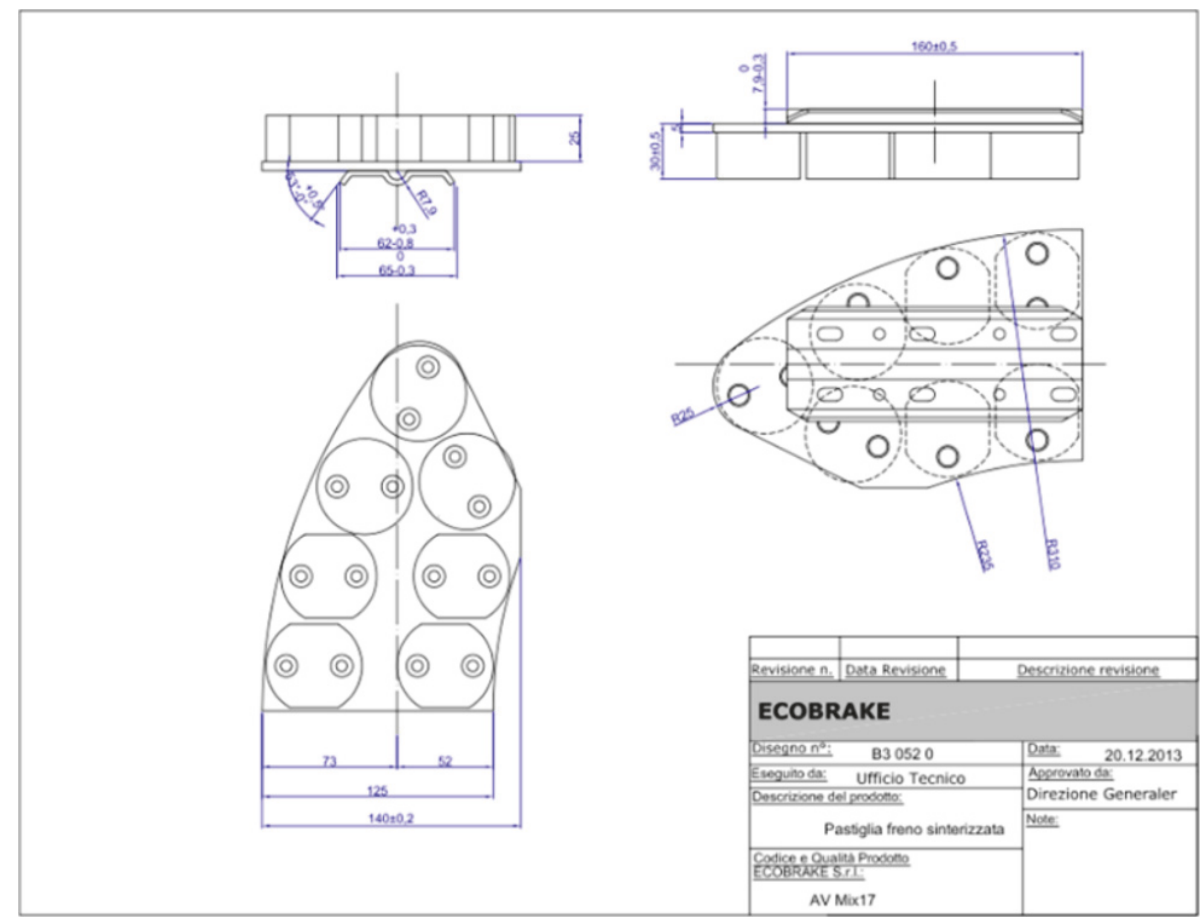

Figure 1: Disc brake model “AV Mix 17 Ecobrake.”

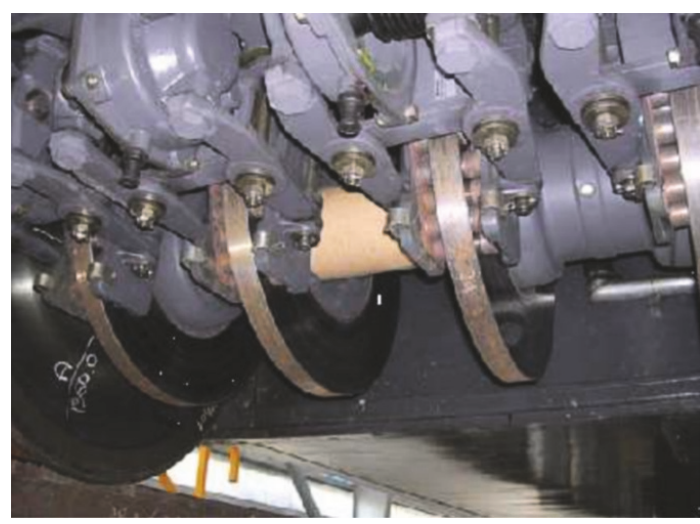

(a)

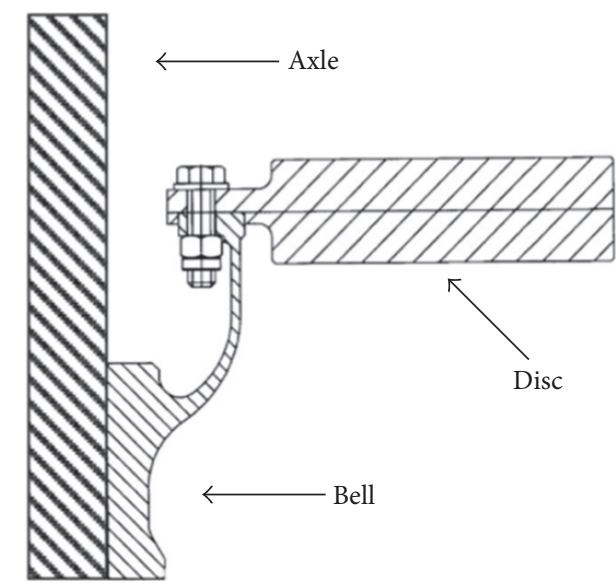

(b)

Figure 2: (a) Disc brake system [17]; (b) structure to join the disc to the axle [16].

in fact, involve only some geometrical features that allow assessing the FE model, proposed in this paper, against the experimental tests carried out by Sinou et al. Finally different strategies to reduce and/or solve the disc brake squeal noise were numerically analyzed, by approaching the problem with a sensitivity analysis.

\section{Test Case Description}

The disc brake model "AV Mix 17 Ecobrake" has been considered in this work; it is produced by "Ecobrake S.u.r.l." for high speed trains of Italian Railway. In this brake model there are 14 cylindrical pads made of sintered material and applicable only to steel discs. The plate and pads design is illustrated in Figure 1 as well as their main sizes.

The disc brake system consists of four discs on each wheel axle and sliding bodies consisting of two symmetric lining plates with cylindrical pads [16]. Brakes are activated by a pneumatic system pressure, and a rotation slowdown of the wheels is determined by pressing brake pads against brake discs. The disc brake system of a high speed train is mounted on a bogie as shown in Figure 2(a). Each disc brake is attached to the axle by means of a "bell" which is a very thin structure clamped to the axle, as shown in Figure 2(b). 


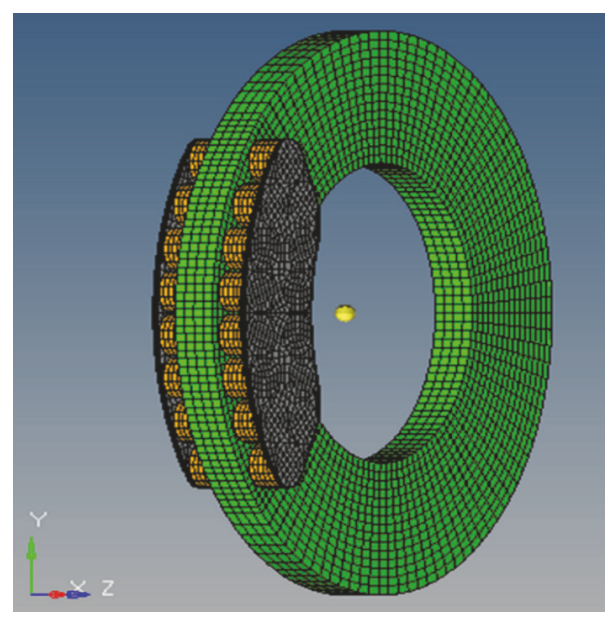

FIGURE 3: FEM model of the brake system.

Concerning the disc geometry, the external and internal radii are $R_{e}=320 \mathrm{~mm}$ and $R_{i}=170 \mathrm{~mm}$, respectively, while the disc thickness is $t=40 \mathrm{~mm}$. The plate and pads design is illustrated in Figure 1, as well as their main sizes.

\section{FE Model}

The brake system has been discretized by means of "HyperMesh $12^{\circledR}$ " software, obtaining a three-dimensional model of the plates, pads, and disc (Figure 3).

Disc and pads have been discretized with 8-node hexahedral elements; plates have been modeled with 8-node hexahedral and 6-node pentahedral elements for the greater shape complexity. The full model is composed of 23576 nodes and 16920 elements. Regarding the contact between pads and rotor, the Coulomb law has been implemented with a constant friction coefficient $f=0.39$, using a smallsliding formulation. Such coefficient has been provided by the technical specifications of the AV Mix 17 Ecobrake.

This developed FE model has been used to perform 4 analyses: the first two steps are nonlinear static procedures, where braking pressure and angular velocity account for effects of compression force and rotor speed in the final sensitivity study; the other two steps consist in the search of system's natural frequencies and the extraction of complex eigenvalues, representing an index of stability for braking system, as said in the previous section. The simulations have been carried out using “Abaqus ${ }^{\circledR}$ v. 6.12" code [23].

Concerning the first structural analysis, it consisted in simulating the pressure introduced by the brake pads on the disc when it is stationary. In this step, the friction coefficient is fixed to be zero and a pressure of $1 \mathrm{MPa}$ has been applied. The second analysis consisted in applying a rotation to the disc, by keeping the value of the pressure brake blades constant. Under this analysis, as suggested by the technical specification, a constant friction coefficient of 0.39 has been introduced. The friction coefficient should fall down when the "creepage" increases. This phenomenon has not been considered in the numerical model. Neglecting the

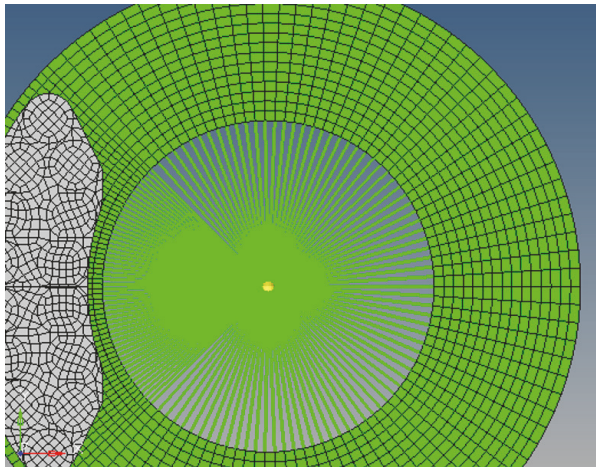

FIGURE 4: Boundary conditions.

creepage effect has been assumed as one of the possible causes of the approximation of numerical results with respect to experimental ones. This analysis has been carried out by means of an implicit formulation.

Moreover, a uniform and constant pressure, equal to $1 \mathrm{MPa}$, has been applied on the plates, to model the maximum braking force condition, and a rotational velocity of $6 \mathrm{rad} / \mathrm{s}$ has been imposed to model braking at low velocity. Such values coincide with those used for the experimental tests [17].

Concerning the boundary conditions, the whole disc has been fully constrained. In particular, all nodes placed in correspondence of the internal diameter have been cinematically linked to a reference point, placed in the center of the disc. Then, the displacements and rotations of this point have been constrained (Figure 4). Another constraint involved the brake plates, allowing them to move only perpendicularly to the disc.

The extraction of the natural frequencies has been performed by defining the Lanczos algorithm as eigen-solver; the natural frequencies have been analyzed in the constrained configuration.

Meanwhile, relatively to the extraction of the complex eigenvalues for the brake squeal analysis, 3 steps should be carried out:

(1) the stability analysis of the system (by using the Routh-Hurwitz criterion or complex eigenvalues analysis);

(2) the nonlinear vibrational behavior via time integration or nonlinear method $[24,25]$;

(3) acoustic analysis and noise performed via specific approaches $[23,26,27]$.

According to this paper, the Routh-Hurwitz criterion has been used, firstly; the second step consisted of the solution of the transient equations of system motion, and finally, regarding the last step, the complex eigenvalue analysis has been performed.

The Routh-Hurwitz criterion is a method for determining the right-hand or left-hand side location of zeros of polynomials, with constant real coefficient on the $s$-plane without actually solving the equation. This criterion indicates the 


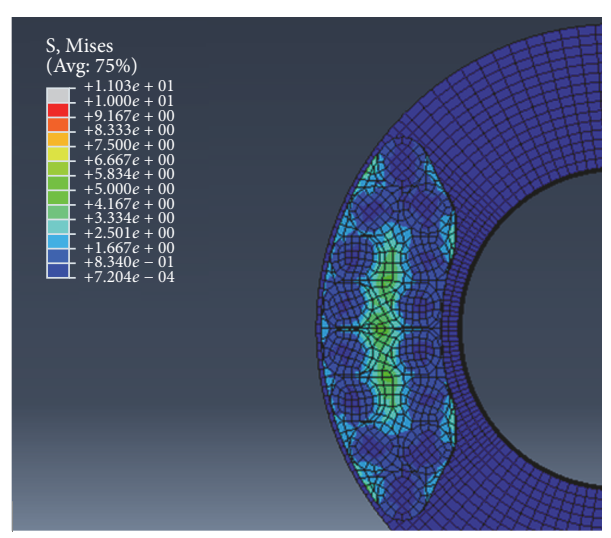

(a)

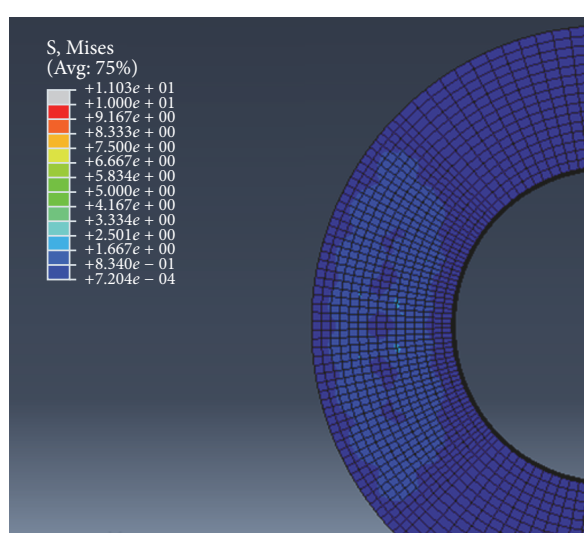

(b)

Figure 5: (a) Von Mises stresses maps involving the front (a) and back (b) views.

absolute stability of the system but does not give information about relative stability. The advantage is that it does not require the solution of the characteristic equation.

Transient solution of the equations of system motion would indicate the presence of initially increasing amplitude or overshoot for a stable system as well as a true instability, but it does not indicate which mode is responsible for such unstable behavior. Moreover, for high frequency vibrations such as squeal, the analysis may be computationally intensive as the time steps need to be sufficiently small.

Complex eigenvalue analysis can predict all modes of the system with the real part of an eigenvalue indicating the stability of the mode and the imaginary part its frequency. This would allow correlation with experimental squeal results, and the unstable modes could be made the focus of an attempt to eliminate squeal. In detail, the results, when displayed on the complex plane (also known as the $s$-plane), clearly indicate the relative stability of modes, and the root locus diagram may be used to track the progressive instability of the considered mode.

Even when damping is ignored, the eigenvalue of a system may still be complex, because the inclusion of a friction matrix produces an unsymmetrical stiffness matrix that, even if made of real terms, can have complex eigenvalues.

Even if in this paper, the effect of the damping modeling has not been investigated, one of the main contributions and well-known issues with brake squeal models is the influence of damping on CEA. Great care should therefore be taken in modeling the damping. It has been known for a long time that the structure of the damping matrix (and not only the magnitude of the damping) is extremely important for the stability and for the dispersion of sequel noise [28-32].

The advantages of complex eigenvalue analysis over the other methods for instability identification are obvious, with the main strength points residing in the ability to clearly identify the unstable modes responsible for squeal. Therefore, the method of complex eigenvalue analysis has been adopted during the presented research activities.

Recently, the numerical methods, in particular the FE one, have become indispensable tools for modeling disc

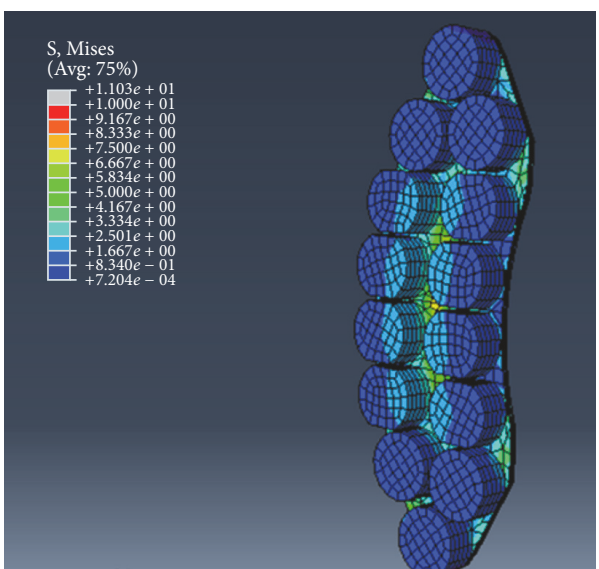

Figure 6: Von Mises stresses map involving the disc blade.

brake systems and providing new insights into the problem of brake squeal. The FE Method provides a natural and straightforward means for generating finite dimensional approximations to the governing equations of motion for the components of the brake system [33-35]. Contrary to traditional lumped parameter techniques, $\mathrm{FE}$ analyses allow an accurate representation of complex geometries and boundary conditions. Therefore, it is possible to simulate the response of the brake system with a higher degree of fidelity [25].

In order to study a brake squeal, FE analyses can be carried out to compute $M$ (mass) and $K$ (stiffness) matrices of disc brakes' models. Subsequently, an eigenvalue analysis is conducted to determine the system frequencies, modes, and stability.

\section{Results}

4.1. Structural Analyses. According to the first structural analysis, Figure 5 shows the contour plots of the Von Mises stresses of both disc sides, while Figure 6 shows the Von Mises stresses map involving the disc blade. 


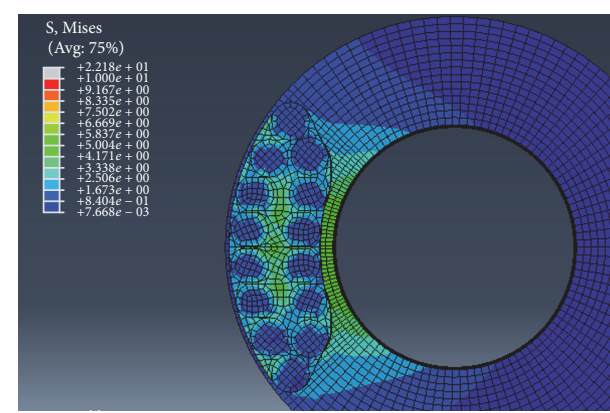

(a)

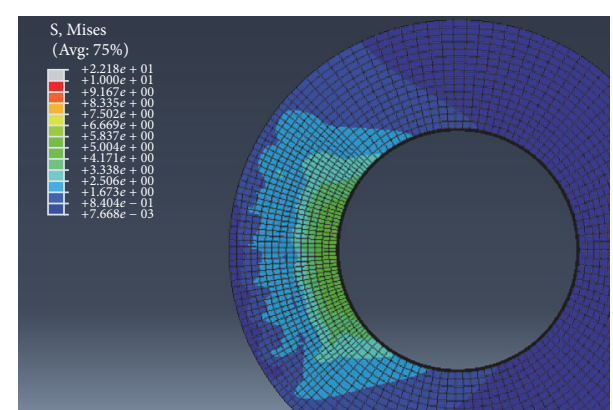

(b)

Figure 7: (a) Von Mises stresses maps involving the front (a) and back (b) views (disc in movement).

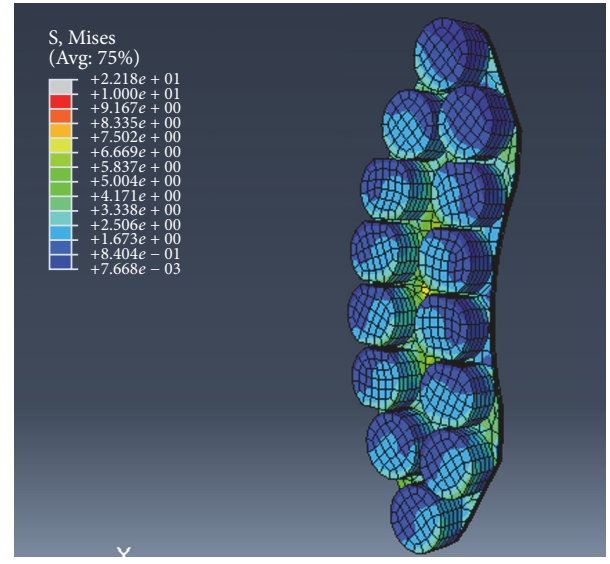

FIGURE 8: Von Mises stresses map involving the disc blade (disc in movement).

When a rotational motion of $6 \mathrm{rad} / \mathrm{s}$ is imposed to the disc, the stresses map changes according to Figures 7 and 8.

According to Figures 7 and 8, due to the disc rotational motion, the Von Mises stresses map changes with respect to static configuration. Obviously, caused by the friction coefficient at the interface between pads and disc, the pads are affected by tangential loads. Analogously, also the disc has an increment in the stress field.

4.2. Natural Frequencies Analysis and the Extraction of Complex Eigenvalues. The first 50 eigenvalues given by the numerical solution, corresponding to a braking pressure $p=$ $1 \mathrm{MPa}$ and a velocity $v=6 \mathrm{rad} / \mathrm{s}$, are reported in Table 1 . In addition to the real part of eigenvalues and to the frequency of vibrational modes, the effective damping ratios for each mode and for the generic eigenvalues, calculated by (1), are listed in Table 1 as well.

$$
\xi=-2 \cdot \frac{(\operatorname{Re}(s))}{|\operatorname{Im}(s)|} .
$$

Thus, the unstable modes (italicized rows in Table 1), characterized by a positive real part of eigenvalue, will have a negative damping ratio. In the first 45 complex eigenvalues, it is possible to recognize 13 vibrational unstable modes.

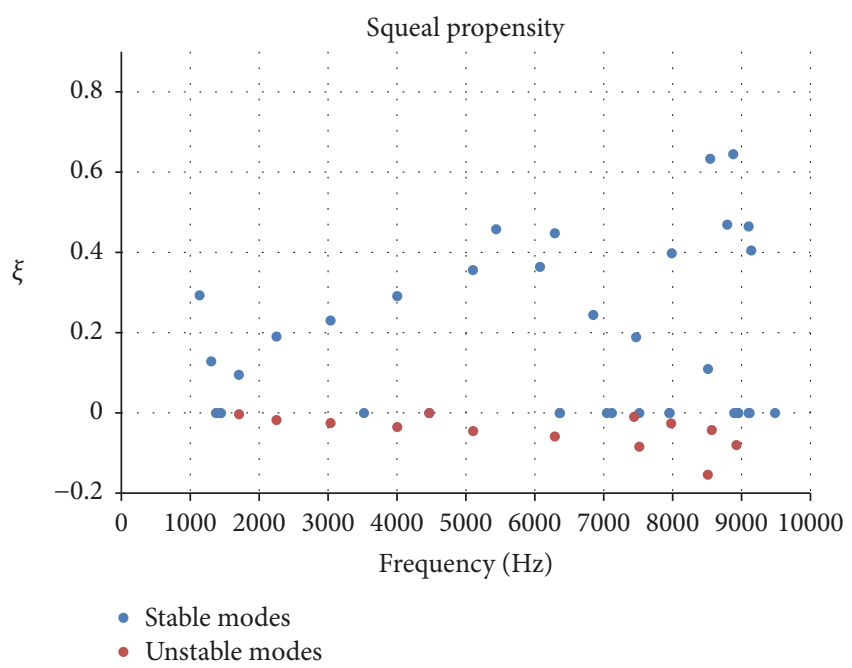

FIGURE 9: Damping ratios for $p=1 \mathrm{MPa}$ and $v=6 \mathrm{rad} / \mathrm{s}$.

Their frequency values are between $1705.5 \mathrm{~Hz}$ and $8923.1 \mathrm{~Hz}$ and they represent a potential source of brake disc squeal. The damping ratios of the first 50 modes are shown in Figure 9, with marker-points highlighted in red representing the unstable modes; these are distributed uniformly between $1000 \mathrm{~Hz}$ and $6300 \mathrm{~Hz}$, with damping ratio values decreasing after $7000 \mathrm{~Hz}$.

The magnitude of eigenvalue real part (damping ratios) does not predict the relative amplitude, hence, the sound pressure level due to each mode; it only reveals how fast the vibration is growing and it is only a relative measure of squeal propensity, in the sense that a mode with large real part is more likely to manifest itself as squeal.

In order to verify the accuracy of these numerical results, a comparison with values obtained experimentally is provided. The evaluation of the squeal prediction and the dynamic behavior of the railway brake system under working conditions are performed on the TGV disc brake, which is very similar to our model in terms of geometry, mass, and stiffness [17]. Numerical and experimental (as extracted from literature [17]) results are reported in Table 2. The numerical results are in good agreement with experimental ones except 
TABLE 1: First 50 eigenvalues for $p=1 \mathrm{MPa}$ and $v=6 \mathrm{rad} / \mathrm{s}$.

\begin{tabular}{|c|c|c|c|c|}
\hline \multirow{2}{*}{ Mode } & \multirow{2}{*}{ Real part of eigenvalue } & \multicolumn{2}{|c|}{ Frequency } & \multirow{2}{*}{ Effective damping ratio } \\
\hline & & {$[\mathrm{rad} / \mathrm{s}]$} & {$[\mathrm{Hz}]$} & \\
\hline 1 & -150.3 & 7127.9 & 1134.4 & 0.0422 \\
\hline 2 & -75.851 & 8189.6 & 1303.4 & 0.0185 \\
\hline 3 & -0.664 & 8622.4 & 1372.3 & 0.00015 \\
\hline 4 & -13.554 & 8923.1 & 1420.2 & 0.00304 \\
\hline 5 & -9.177 & 9079.1 & 1445.0 & 0.00202 \\
\hline 6 & -73.194 & 10712 & 1704.9 & 0.0137 \\
\hline 7 & 18.409 & 10716 & 1705.5 & -0.00344 \\
\hline 8 & -193.38 & 14128 & 2248.5 & 0.0274 \\
\hline 9 & 124.07 & 14135 & 2249.7 & -0.0175 \\
\hline 10 & -316.40 & 19068 & 3034.8 & 0.0332 \\
\hline 11 & 240.46 & 19073 & 3035.5 & -0.0252 \\
\hline 12 & $-1.265 e-5$ & 22112 & 3519.2 & 0.000 \\
\hline 13 & -527.22 & 25145 & 4001.9 & 0.0419 \\
\hline 14 & 441.66 & 25149 & 4002.6 & -0.0351 \\
\hline 15 & 5.235 & 28059 & 4465.8 & -0.00037 \\
\hline 16 & -11.451 & 28061 & 4466.0 & 0.00082 \\
\hline 17 & -821.93 & 32053 & 51015.4 & 0.0513 \\
\hline 18 & 724.22 & 32057 & 5102.1 & -0.0452 \\
\hline 19 & -1140.2 & 34165 & 5509.1 & 0.0659 \\
\hline 20 & -1000.5 & 38163 & 6073.9 & 0.0524 \\
\hline 21 & 1161.2 & 39509 & 6288.0 & -0.0588 \\
\hline 22 & -1275.3 & 39515 & 6289.0 & 0.0645 \\
\hline 23 & -1.074 & 39967 & 6360.9 & 0.000 \\
\hline 24 & -40.348 & 39968 & 6361.2 & 0.00202 \\
\hline 25 & -757.71 & 43009 & 6845.0 & 0.0352 \\
\hline 26 & -72.127 & 44254 & 7043.2 & 0.00326 \\
\hline 27 & -26.081 & 44715 & 7116.6 & 0.00117 \\
\hline 28 & 229.31 & 46747 & 7440.0 & -0.00981 \\
\hline 29 & -637.5 & 46917 & 7467.1 & 0.0272 \\
\hline 30 & -2121.9 & 47214 & 7514.3 & 0.899 \\
\hline 31 & 1979.6 & 47217 & 7514.8 & -0.0838 \\
\hline 32 & -99.876 & 49954 & 7950.5 & 0.00400 \\
\hline 33 & -51.561 & 49968 & 7952.6 & 0.00206 \\
\hline 34 & 652.73 & 50113 & 7975.8 & -0.0260 \\
\hline 35 & -1437.5 & 50182 & 7986.7 & 0.0573 \\
\hline 36 & 4130.2 & 53460 & 8508.4 & -0.154 \\
\hline 37 & -4239.8 & 53473 & 8510.4 & 0.158 \\
\hline 38 & -2447.1 & 53686 & 8544.5 & 0.0912 \\
\hline 39 & 1141.7 & 53829 & 8567.2 & -0.0424 \\
\hline 40 & -1866.0 & 55226 & 8789.5 & 0.0676 \\
\hline 41 & -2591.2 & 55774 & 8876.7 & 0.0929 \\
\hline 42 & -2042.7 & 55863 & 8890.9 & 0.07313 \\
\hline 43 & 2240.1 & 56065 & 8923.1 & -0.0799 \\
\hline 44 & -173.2 & 56217 & 8947.3 & 0.00616 \\
\hline 45 & -17.507 & 56232 & 8949.6 & 0.00062 \\
\hline 46 & -1913.6 & 57182 & 9100.7 & 0.0669 \\
\hline 47 & -65.943 & 57182 & 9100.7 & 0.00231 \\
\hline 48 & -285.61 & 57268 & 9114.4 & 0.00997 \\
\hline 49 & -1673.4 & 57429 & 9140.1 & 0.0583 \\
\hline 50 & -79.304 & 59588 & 9483.8 & 0.00266 \\
\hline
\end{tabular}


TABLE 2: Comparison between numerical results and experimental ones given by [17].

\begin{tabular}{lcccccccc}
\hline Numerical results [Hz] & - & 1706 & 2250 & 3036 & 4003 & 6288 & 7440 & 7976 \\
\hline Experimental results [Hz] [17] & 1200 & 1700 & 2100 & 3200 & 3900 & 5700 & 7100 & 8000 \\
\hline Difference [\%] & & 0.32 & 7.13 & -5.14 & 2.63 & 10.32 & 4.79 & -0.30 \\
\hline
\end{tabular}

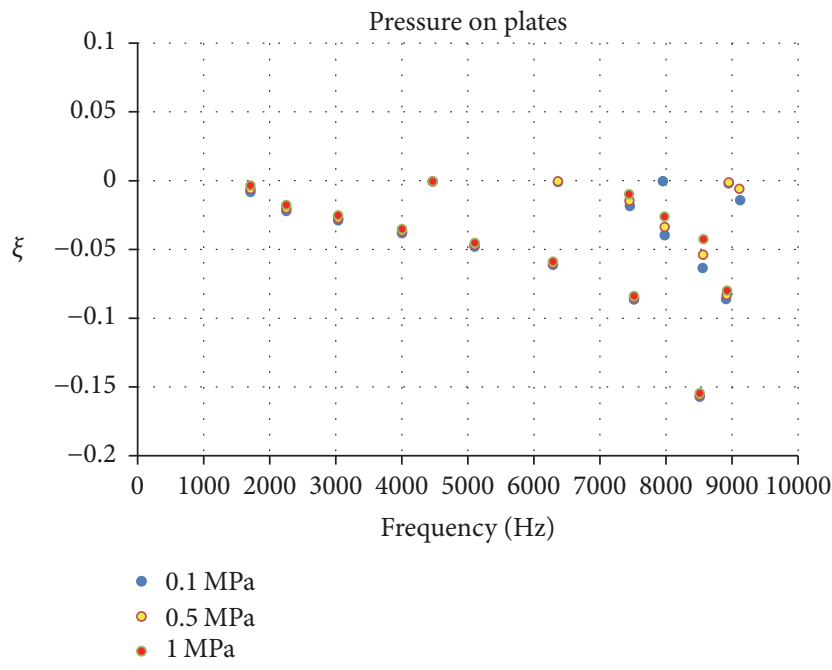

FIGURE 10: Damping ratios for different values of pressure and $v=$ $6 \mathrm{rad} / \mathrm{s}$.

for the first natural frequency that the numerical model does not predict.

\section{Parametric Study of Braking System}

For this sensitivity analysis, both the boundary conditions and braking system geometry have been considered as parameters. In particular, the evolution of the system stability will be highlighted, first, by varying some parameters, like

(i) pressure on the plates;

(ii) rotational velocity of disc.

Then, the effects on the system stability will be considered, as produced by variation of parameters like

(i) disc thickness;

(ii) plates thickness;

(iii) friction material.

5.1. Effect of Pressure on Plates. In the squeal propensity study, the first considered parameter is the braking pressure applied on plates. Since $p=1 \mathrm{MPa}$ represents the maximum pressure value available for the sensitivity analysis, all the other tested values will be lower. In this case, uniform pressure values 0.1 $\mathrm{MPa}$, 0.5 $\mathrm{MPa}$, and $1 \mathrm{MPa}$ were considered. Damping ratios of the unstable modes corresponding to the three pressure conditions and to a rotational velocity of $6 \mathrm{rad} / \mathrm{s}$ are shown in Figure 10: the number of unstable modes decreases

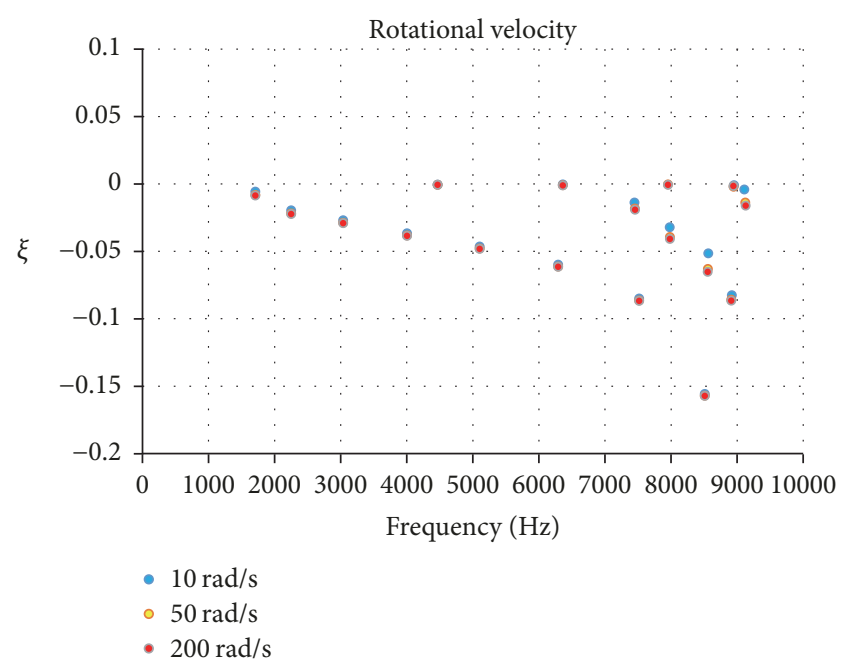

FIGURE 11: Damping ratios for different values of rotational velocity and $p=1 \mathrm{MPa}$.

when increasing the braking pressure applied on the plates, whereas damping ratios increase with pressure, especially between $7000 \mathrm{~Hz}$ and $9000 \mathrm{~Hz}$. Thus, the system instability (i.e., the squeal propensity) can be reduced by increasing the normal force on the plates, as just explained by the earlier lumped parameter models.

The key-reading of Figure 10 is that the unstable modes, characterized by a positive real part of eigenvalue, have a negative damping ratio, representing a potential source of brake disc squeal; the key-reading of the following figures is the same.

5.2. Effect of Rotational Velocity. The second parameter evaluated is the rotational velocity of the disc. As the brake model considered in the present study is designed for a high speed train, a large variation range for this parameter has been considered; in particular, angular velocities of $10 \mathrm{rad} / \mathrm{s}, 50 \mathrm{rad} / \mathrm{s}$, and $200 \mathrm{rad} / \mathrm{s}$ have been imposed, applying the braking pressure of $p=1 \mathrm{MPa}$. The numerically evaluated damping ratio values are presented in Figure 11. Almost all points of the graph show essentially no difference against velocity values, especially those related to the speed of $50 \mathrm{rad} / \mathrm{s}$ and $200 \mathrm{rad} / \mathrm{s}$. This invariance of squeal propensity versus rotational velocity is likely in connection with the initial hypothesis of Coulombian friction; in fact, considering the friction coefficient constant with angular speed, also the friction force will be constant, which represents energy source of self-excited vibrations that cause the squeal, so a nonconstant friction coefficient should be considered. 


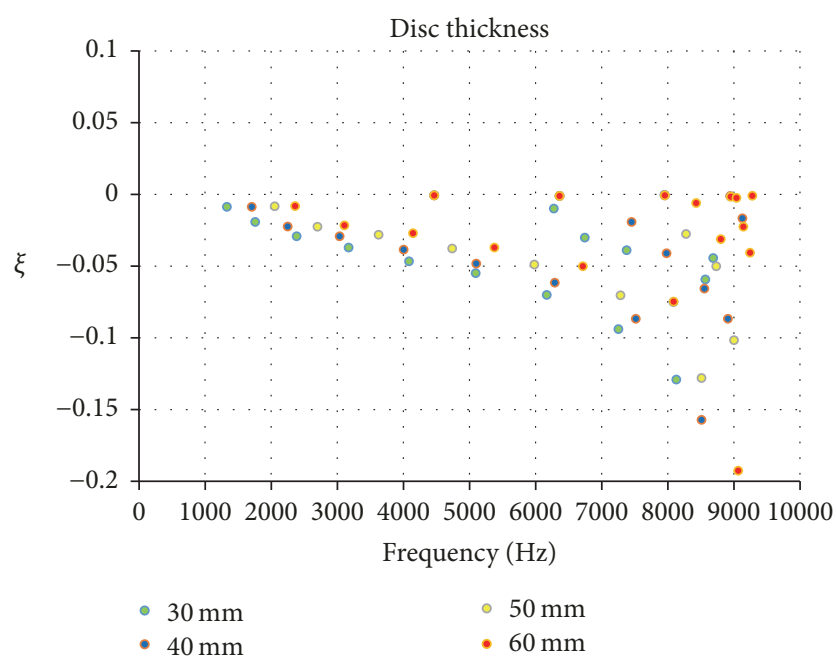

FIGURE 12: Damping ratios for different values of disc thickness, $p=$ $0.1 \mathrm{MPa}$, and $v=50 \mathrm{rad} / \mathrm{s}$.

5.3. Effect of Disc Thickness. In order to evaluate the influence of disc thickness, the following conditions have been imposed: a pressure on the plates $p=0.1 \mathrm{MPa}$ and an angular velocity $v=50 \mathrm{rad} / \mathrm{s}$, representing the average conditions that involve the disc of a train approaching the railway station, during the braking phase. Simulations have been performed with variable thickness in the range between $30 \mathrm{~mm}$ and $60 \mathrm{~mm}$. The damping ratios of unstable modes are shown in Figure 12. Looking at the results, it is possible to state that the number of unstable modes, related to a disc diameter of $30 \mathrm{~mm}$, is maximum, whereas it becomes minimum for a disc diameter of $50 \mathrm{~mm}$; then, increasing the thickness, the frequencies and the damping ratios of unstable modes increase (the system stiffness increases more than its mass). Thus, the thickness increase improves the system stability, except for the mode that occurs at nearly $9000 \mathrm{~Hz}$, considering the first 50 modes for a disc diameter of $60 \mathrm{~mm}$.

5.4. Effect of Plate Thickness. The plate thickness was varied between $3 \mathrm{~mm}$ and $15 \mathrm{~mm}$. The damping ratios of unstable modes for a braking pressure $p=0.1 \mathrm{MPa}$ and a rotational speed $v=50 \mathrm{rad} / \mathrm{s}$ are displayed in Figure 13. In this case, it can be seen that the $5 \mathrm{~mm}$ thick plates provide the worst results, especially at higher frequencies; the best results are achieved with the $15 \mathrm{~mm}$ thick plates, because this gives the highest damping ratios over the entire frequency range represented; on the other hand, such a thickness involves a heavy component oversizing.

5.5. Effect of Friction Materials. Alternatively to the sintered material, an organic material (asbestos free) can be used for the pads. As for the previous cases, the term of comparison for measuring the squeal propensity is the damping ratio of unstable modes. These are represented in Figure 14, for the operative condition corresponding to pressure on plates of $p=0.1 \mathrm{MPa}$ and angular velocity of $v=50 \mathrm{rad} / \mathrm{s}$ : the use of organic material for the pads provides benefits in relation to

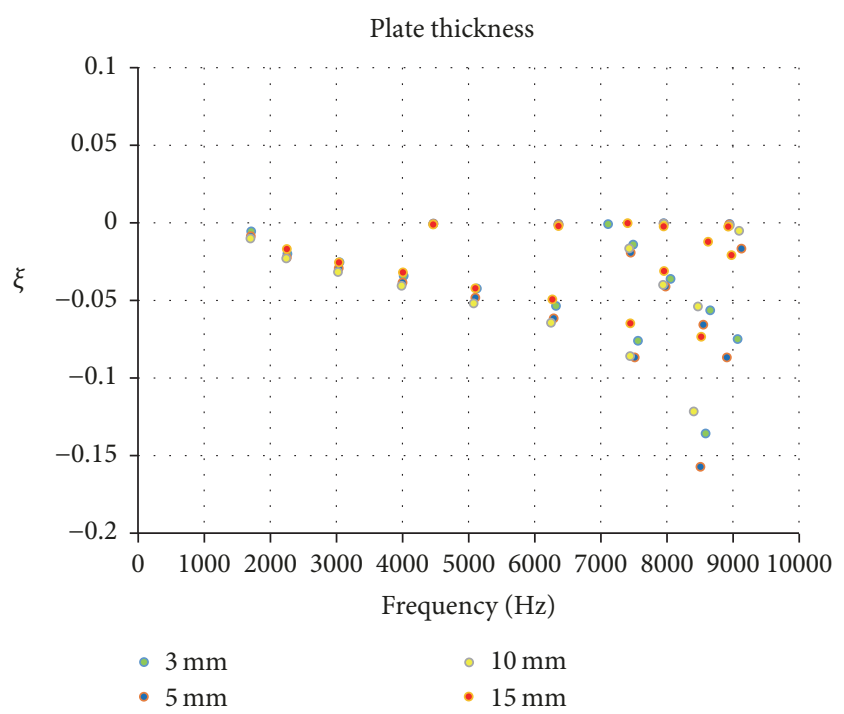

FIGURE 13: Damping ratios for different values of plate thickness, $p$ $=0.1 \mathrm{MPa}$, and $v=50 \mathrm{rad} / \mathrm{s}$.

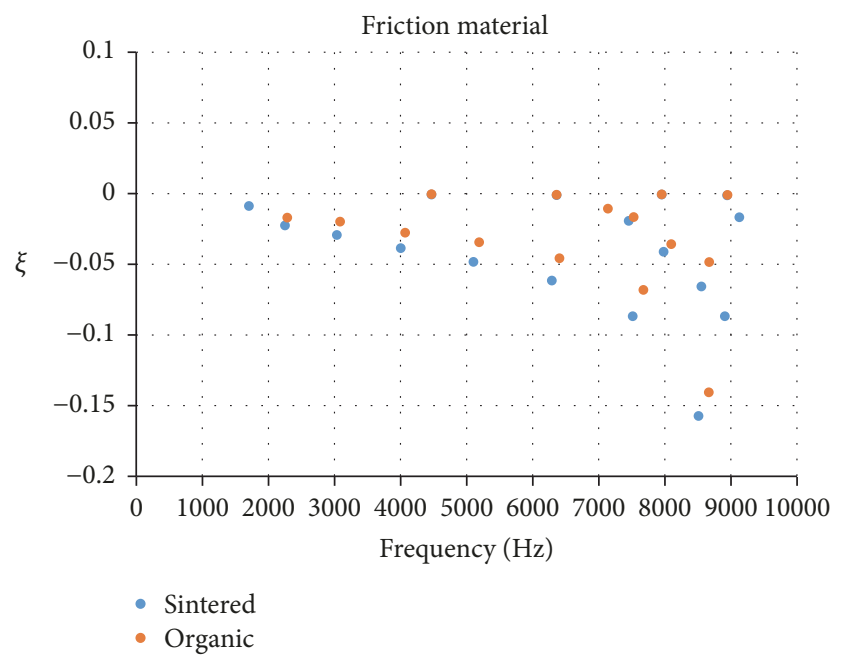

FIGURE 14: Damping ratios for different friction pads material, $p=$ $0.1 \mathrm{MPa}$, and $v=50 \mathrm{rad} / \mathrm{s}$.

the stability system over the entire frequency range observed. This improvement is due to a higher damping supplied by the organic material, which ensures better dissipation of mechanical energy; therefore, the organic pads represent a valid solution for reducing the squeal propensity of disc brake system.

\section{Conclusions}

In this paper the propensity to generate squeal noise by a disc brake for a TGV has been investigated by means of a numerical model based on FE Method. A complete FE model of the brake system has been developed to model vibration instabilities at the origin of disc brake squeal. The investigation has been carried out under a braking pressure of $1 \mathrm{MPa}$ and a velocity of $6 \mathrm{rad} / \mathrm{s}$. The investigation allowed 
recognizing 13 vibrational unstable modes, representing a potential source of brake disc squeal, within the frequency range: $1705.5 \mathrm{~Hz} \div 8923.1 \mathrm{~Hz}$. The numerical results are in good agreement with the experimental tests for the prediction of brake squeal.

Also a sensitivity analysis has been carried out in order to evaluate the stability of brake system when varying the following parameters: pressure on the plates, rotational velocity of disc, disc thickness, plate's thickness, and friction material.

In particular, it has been found out that the number of unstable modes decreases when increasing the braking pressure applied on the plates (Figure 10); the disc thickness increase improves the system stability (Figure 12); higher thick plates values provided the best results, leading to the highest damping ratios over the entire frequency range (Figure 13); the use of organic material for the pads provides benefits (Figure 14) in relation to the stability system over the entire frequency range observed (this improvement is due to a higher damping supplied by the organic material, which ensures better dissipation of mechanical energy). Concerning the effects of the rotational velocity (Figure 11), by considering the friction coefficient constant with the angular speed, also the friction force will be constant, which represents energy source of self-excited vibrations that cause the squeal. Thus, a nonconstant friction coefficient should be considered and further investigations are mandatory.

\section{Conflicts of Interest}

The authors declare that there are no conflicts of interest regarding the publication of this paper.

\section{Acknowledgments}

The authors thank Professor R. A. Romano for the scientific and technical support.

\section{References}

[1] D. J. Thompson and C. J. C. Jones, "Review of the modelling of wheel/rail noise generation," Journal of Sound and Vibration, vol. 231, no. 3, pp. 519-536, 2000.

[2] Green Paper of the European Commission, "Future Noise Policy," COM(96) 540 final, Brussels, 4th November 1996.

[3] WG Railway Noise of the European Commission, "Position Paper on the European strategies and priorities for railway noise abatement," 2003.

[4] C. J. C. Jones and J. W. Edwards, "Development of wheels and track components for reducing rolling noise from freight trains," in Proceedings of Internoise, Liverpool, UK, 1996.

[5] P. Fodiman, "Line test validation of low noise railway components," in Proceedings of World Congress on Railway Research, Colorado, CO, USA, 1996.

[6] L. Guccia, "Synthése finale des travaux groupe de travil bruit de roulement MONA-RONA-VONA," report RVA/LG/roult/c/ 970729, SNCF Direction de la Recherche, 1997.

[7] P. Fodiman, L. Castel, and G. Gaborit, "Validation of a TGV-a travelling-car wheel with an acoustically optimized profile," in Proceedings of 11th International Wheelset Congress, Parigi, France, 1995.

[8] L. Guccia, P. Fodiman, P. E. Gautier, N. Vincent, and P. Bouvet, "High-speed rolling noise design and validation of low noise components," in Proceedings of World Congress on Railway Research, Firenze, Italia, 1997.

[9] B. Hemsworth, P. E. Gautier, and R. Jones, "Silent freight and silent track projects," in Proceedings of the Internoise 2000, vol. 31, pp. 24-27, Nice, France, 2000.

[10] B. Hemsworth, Silent Freight/Silent Track/Eurosabot projects-Summary, ERRI, Utrecht, The Netherlands, 2001.

[11] B. Hemsworth and R. R. K. Jones, Silent Freight Project_Final Report, ERRI, Utrecht, The Netherlands, 2000.

[12] B. Hemswort, Silent Track Project-Final Report, ERRI, Utrecht, The Netherlands, 2000.

[13] P. de Vos and S. van Lier, "Noise-related roughness on railway wheels generated by tread braking," in Proceedings of the Internoise 2000, vol. 31, pp. 24-27, Nice, France, 2000.

[14] J. Lub, "The quiet rail traffic (STV) project. Part 2 demonstrating practical low noise solutions," in Proceedings of the Joint EAA/ASA/DEGA Meeting on Acoustics, Berlin, Germany, 1999.

[15] J. Lub, "Een moedige speurtocht naar stiller treinverkeer: het project STV," in Proceedings of the National Congress on Sound and Vibration, Rotterdam, Holland, 1999.

[16] X. Lorang, F. Foy-Margiocchi, Q. S. Nguyen, and P. E. Gautier, "TGV disc brake squeal," Journal of Sound and Vibration, vol. 293, no. 3-5, pp. 735-746, 2006.

[17] J.-J. Sinou, A. Loyer, O. Chiello et al., "A global strategy based on experiments and simulations for squeal prediction on industrial railway brakes," Journal of Sound and Vibration, vol. 332, no. 20, pp. 5068-5085, 2013.

[18] M. J. Crocker, Handbook of Noise and Vibration Control, John Wiley \& Sons, Inc, 2007.

[19] R. Citarella, L. Federico, and A. Cicatiello, "Modal acoustic transfer vector approach in a FEM-BEM vibro-acoustic analysis," Engineering Analysis with Boundary Elements, vol. 31, no. 3, pp. 248-258, 2007.

[20] R. Citarella and M. Landi, "Acoustic analysis of an exhaust manifold by indirect boundary element method," Open Mechanical Engineering Journal, vol. 5, no. 1, pp. 138-151, 2011.

[21] E. Armentani, R. Trapani, R. Citarella, A. Parente, and M. Pirelli, "FEM-BEM numerical procedure for insertion loss assessment of an engine beauty cover," Open Mechanical Engineering Journal, vol. 7, no. 1, pp. 27-34, 2013.

[22] D. Siano and R. Citarella, "Elastic multi body simulation of a multi-cylinder engine," The Open Mechanical Engineering Journal, vol. 8, no. 1, pp. 157-169, 2014.

[23] S. Oberst, J. C. S. Lai, and S. Marburg, "Guidelines for numerical vibration and acoustic analysis of disc brake squeal using simple models of brake systems," Journal of Sound and Vibration, vol. 332, no. 9, pp. 2284-2299, 2013.

[24] N. Coudeyras, S. Nacivet, and J.-J. Sinou, "Periodic and quasiperiodic solutions for multi-instabilities involved in brake squeal," Journal of Sound and Vibration, vol. 328, no. 4-5, pp. 520-540, 2009.

[25] N. Coudeyras, J.-J. Sinou, and S. Nacivet, "A new treatment for predicting the self-excited vibrations of nonlinear systems with frictional interfaces: the Constrained Harmonic Balance Method, with application to disc brake squeal," Journal of Sound and Vibration, vol. 319, no. 3-5, pp. 1175-1199, 2009. 
[26] K. Soobbarayen, S. Besset, and J.-J. Sinou, "Noise and vibration for a self-excited mechanical system with friction," Applied Acoustics, vol. 74, no. 10, pp. 1191-1204, 2013.

[27] K. Soobbarayen, S. Besset, and J.-J. Sinou, "A simplified approach for the calculation of acoustic emission in the case of friction-induced noise and vibration," Mechanical Systems and Signal Processing, vol. 50-51, pp. 732-756, 2015.

[28] N. Hoffmann and L. Gaul, "Effects of damping on modecoupling instability in friction induced oscillations," Journal of Applied Mathematics and Mechanics, vol. 83, no. 8, pp. 524-534, 2003.

[29] J.-J. Sinou, G. Fritz, and L. Jézéquel, "The role of damping and definition of the robust damping factor for a self-exciting mechanism with constant friction," Journal of Vibration and Acoustics, vol. 129, no. 3, pp. 297-306, 2007.

[30] O. N. Kirillov and A. O. Seyranian, "The effect of small internal and external friction on the stability of distributed nonconservative systems," Journal of Applied Mathematics and Mechanics, vol. 69, no. 4, pp. 584-611, 2005.

[31] G. Fritz, J.-J. Sinou, J.-M. Duffal, and L. Jézéquel, "Effects of damping on brake squeal coalescence patterns-application on a finite element model," Mechanics Research Communications, vol. 34, no. 2, pp. 181-190, 2007.

[32] G. Fritz, J.-J. Sinou, J.-M. Duffal, and L. Jézéquel, "Investigation of the relationship between damping and mode-coupling patterns in case of brake squeal," Journal of Sound and Vibration, vol. 307, no. 3-5, pp. 591-609, 2007.

[33] Z. B. M. Ripin, Analysis Of Disc Brake Squeal Using The Finite Element Method, Department of Mechanical Engineering, University of Leeds, September 1995.

[34] M. T. Júnior, S. N. Y. Gerges, and R. Jordan, Analysis of Brake Squeal Noise Using the Finite Element Method: A Parametric Study, vol. 69, Federal University of Santa Catarina, Mechanical Engineering Department, Acoustics and Vibration Laboratories, University Campus, Trindade, Florianopolis, SC, Brazil, 2007.

[35] "Abaqus 6.12, Analysis User's Manual". 


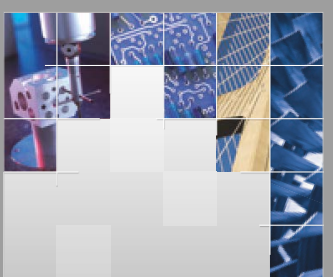

\section{Enfincering}
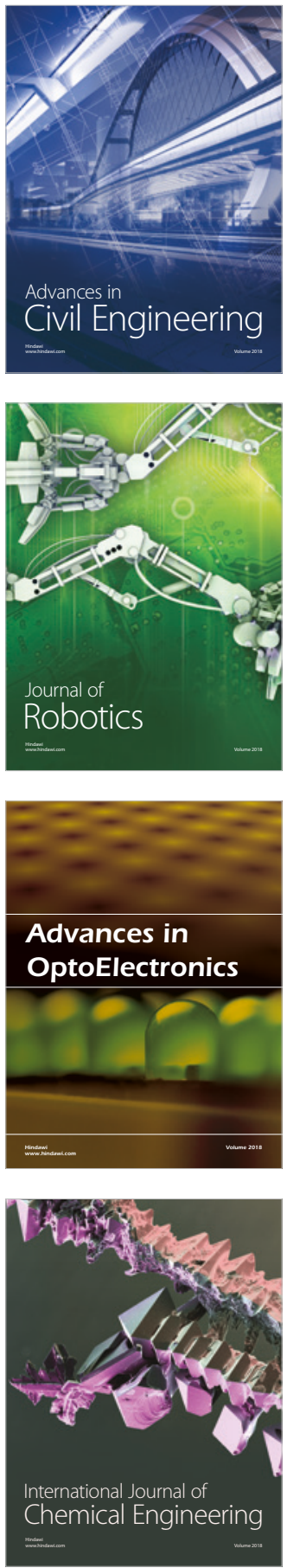

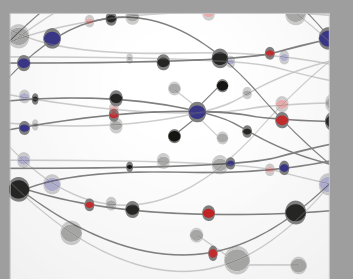

\section{Rotating \\ Machinery}

The Scientific World Journal

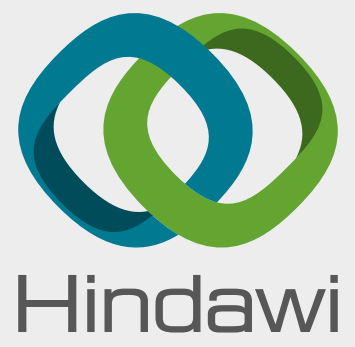

Submit your manuscripts at

www.hindawi.com
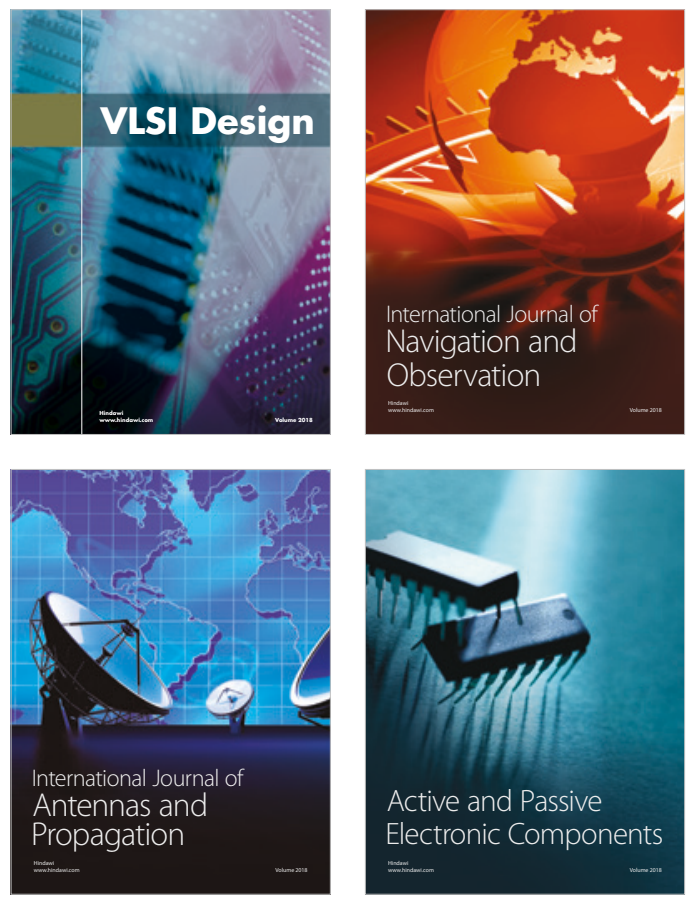
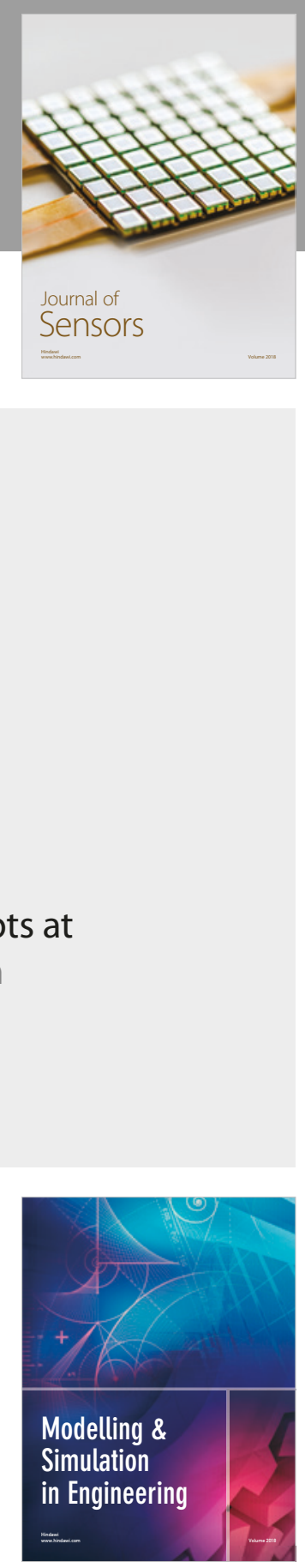

\section{Advances \\ Multimedia}
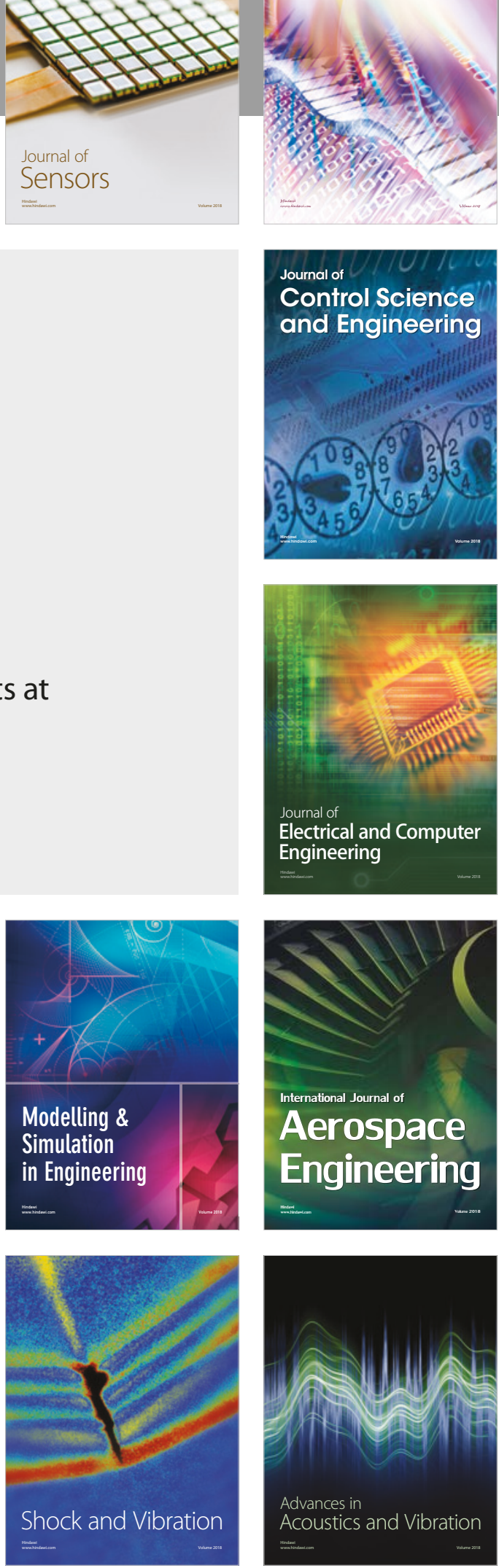